\title{
Recurring abscesses at injection sites on the home injection programme
}

Morag Middleton

Lead Endocrine Nurse Specialist

Endocrine Unit,

JJR Macleod Centre for

Diabetes, Endocrinology

\& Metabolism,

David Anderson Building,

Aberdeen Royal Infirmary

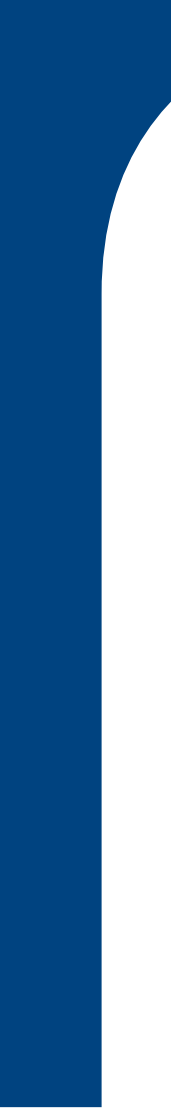

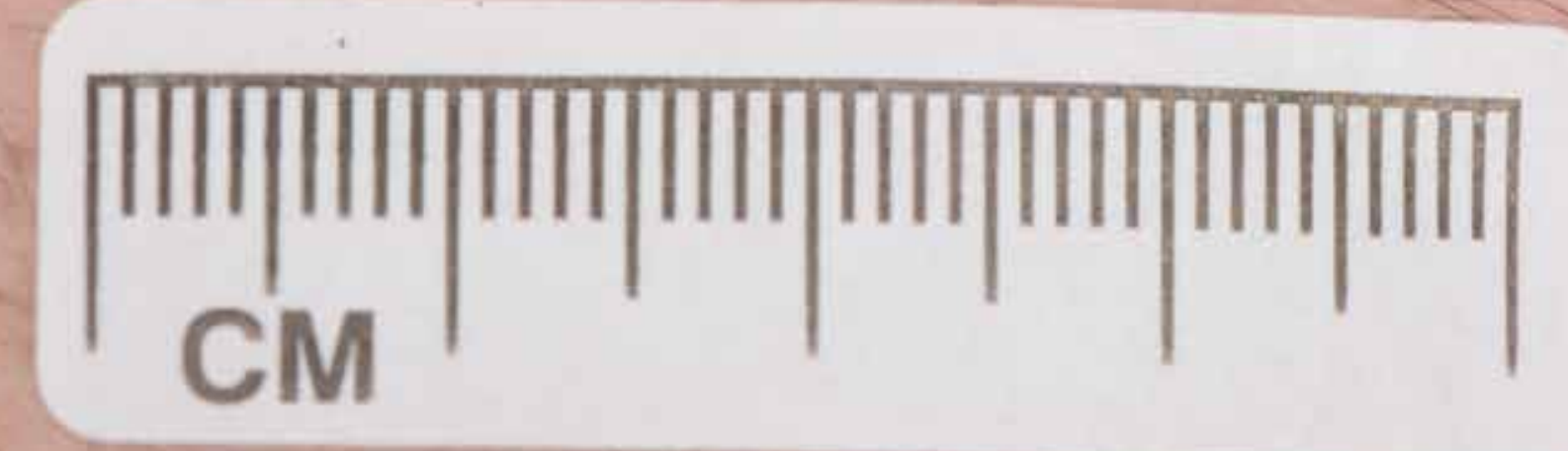

Scar from previous abscess

Acromegaly is a rare clinical condition resulting from prolonged and excessive release of Growth Hormone $(\mathrm{GH})$ from an adenoma within the pituitary gland. Somatostatin analogues are synthetic versions of Somatostatin, a hypothalamic peptide that inhibits pituitary GH release and is administered by monthly injection. This case describes a 31year old gentleman with treated Acromegaly who was well established on a Somatostatin Analogue (Somatuline Autogel) on the home injection programme, suddenly developed abscesses at his injection sites. His mother and partner had received the appropriate training on how to administer the deep subcutaneous monthly injection, with assessment and supervision of their injection technique made by the Lead Endocrine Nurse Specialist.

The first seven injections delivered through the home injection programme were uneventful. The next two injections resulted in abscess formation at the injection sites. This required hospitalisation for excision and drainage and treatment with both intravenous and oral antibiotics. The manufacturer of Somatuline Autogel was contacted to enquire if any known causes and

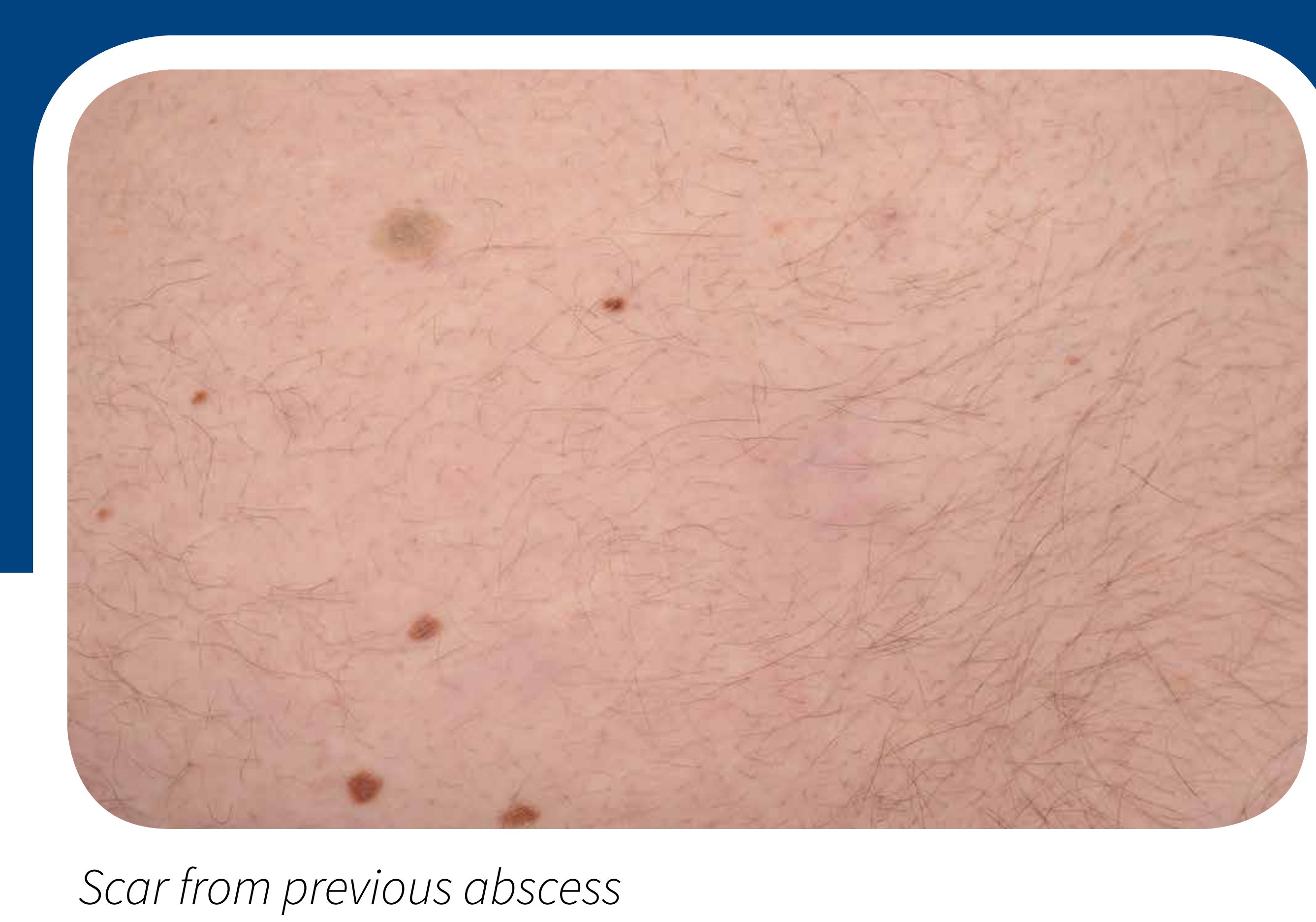

cases were documented with this complication. On reviewing the gentleman it was discovered that he had excessive body hair particularly at the chosen site of the upper outer quadrant of the buttock.

The medical department within the company were unaware of any previous incidences of abscess formation. In discussion with the gentleman, alternative injection sites were identified and preparation of the injection site by shaving the hair proposed.

The next two injections were administered by the Lead Endocrine Nurse Specialist into the upper outer thigh, with the area shaved and cleansed with soap and water prior to injection. No further abscesses developed. Further training was given to his mother and he returned to the home injection programme.

NHS Grampian has utilised the home injection programme to support patients in remote and rural locations throughout Grampian and the Highlands and islands. This enables them to have confidence in self managing their injection therapies.
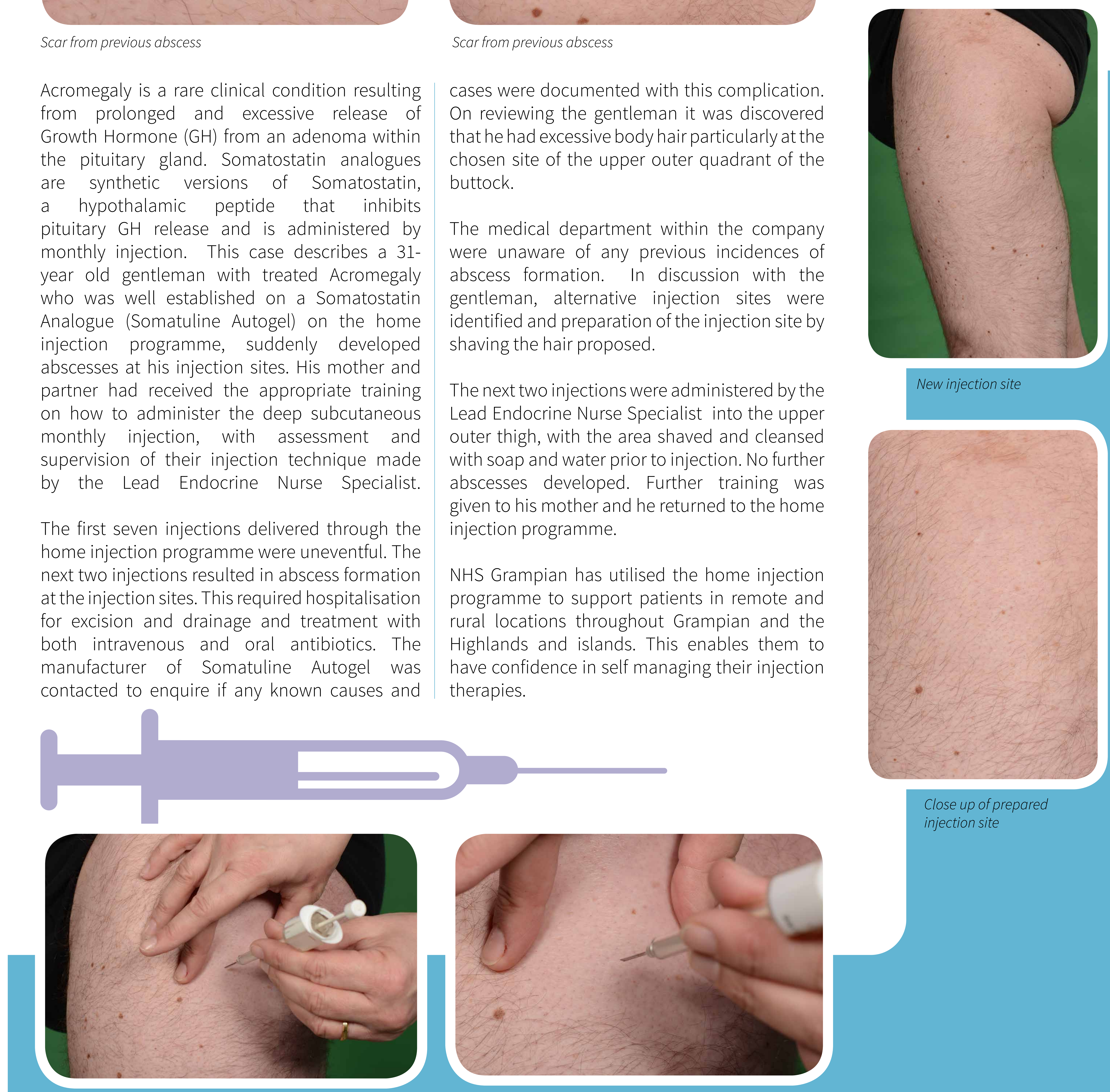

New injection site

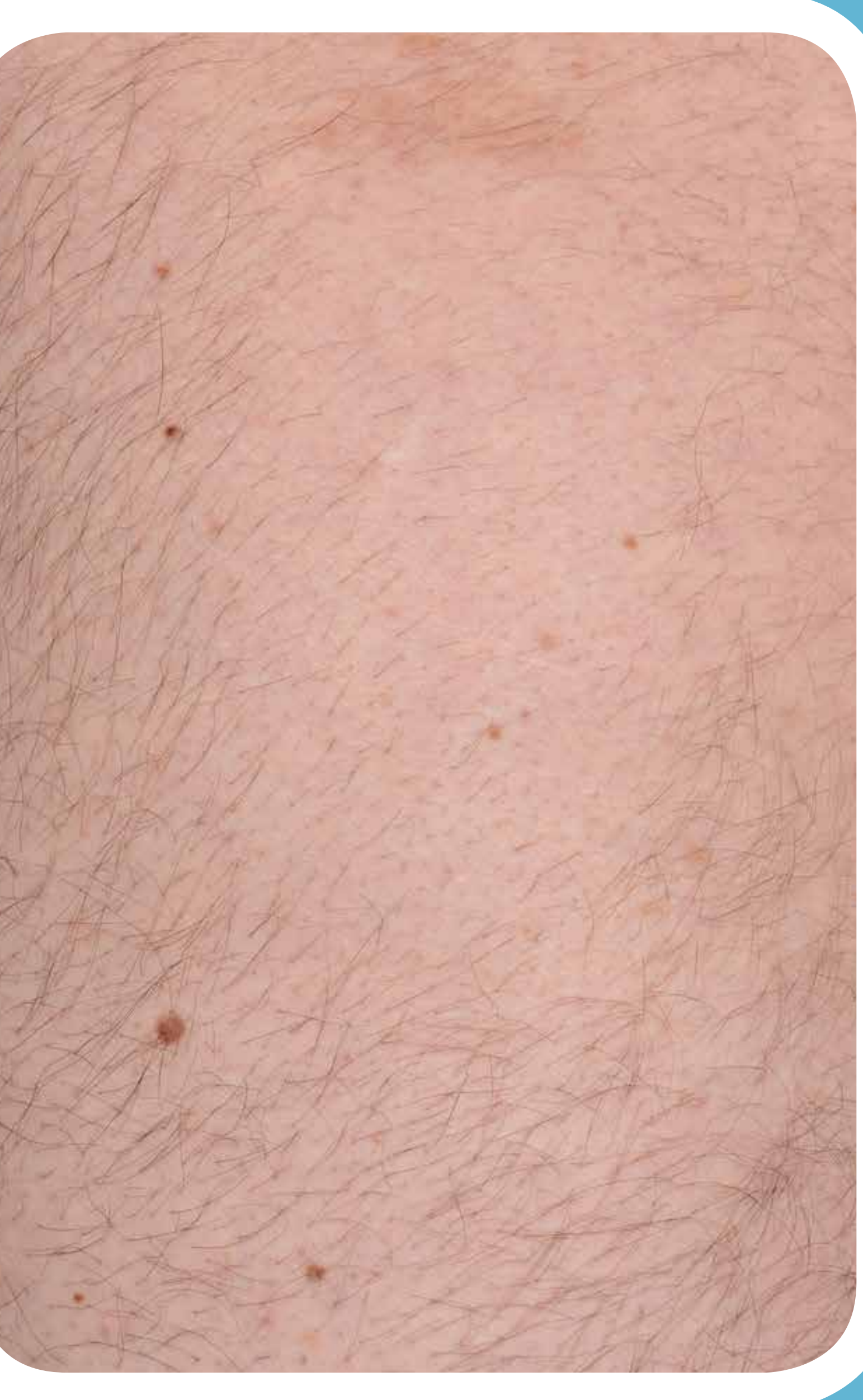

Close up of prepared injection site 